\title{
Cellulose acetate-based carbon xerogels and cryogels
}

\author{
J. Štefelová, M. Mucha \& T. Zelenka \\ Department of Chemistry, Faculty of Science, \\ University of Ostrava, Czech Republic
}

\begin{abstract}
Low density carbonaceous materials based on biosources were prepared from cellulose acetate with a catalyst and a crosslinking agent. Standard preparation of these materials included dissolution, gelation and subsequent drying. In this study, cellulose acetate xerogels or cryogels were prepared, and the influence of the different drying techniques applied was investigated. The internal surface area of cellulose xerogels and cryogels varied from 700 to $850 \mathrm{~m}^{2} \mathrm{~g}^{-1}$, the volume of pores was $0.3 \mathrm{ml} \mathrm{g}^{-1}$. Other properties such as thermal decomposition or surface chemistry were gained and both materials were analysed by adsorption experiments of selected heavy metal and organic dye from aqueous phase. Keywords: cellulose acetate, xerogel, cryogel, freeze-drying.
\end{abstract}

\section{Introduction}

Carbon aerogels are fascinating, unique materials with an extensive porous network, high values of specific surface areas and low densities due to the fact that more than $90 \%$ of their volume is air. Inorganic aerogels made from silica or metal oxides such as zinc, aluminium or titanium are the most common materials. In most cases, organic aerogels are made from resorcinol and formaldehyde or from their derivates by sol-gel synthesis. Cellulose aerogels were firstly prepared by S. Kirstler [1,2]. Cellulose is a renewable material and the most common source of biomass; it is the most abundant biopolymer and has really good properties such as biocompatibility, biodegradability as well as thermal and chemical stability [3]. Cellulose is a fibrous polysaccharide consisting of $\beta$-D-glucopyranosyl units joined by 1,4 -glycosidic bonds. It is 
almost insoluble and represents the major structural component of cell walls of plants [4].

Generally, hydrogels are made by condensation of small polymeric particles. Aggregation of these particles takes place by means of sol-gel process, after that, the sponge-like, three-dimensioned porous network with liquid-filled pores is obtained. The liquid is mostly water or alcohol; therefore the resulting wet gels are named hydrogels or alcogels. When the water or alcohol in pores is replaced by means of supercritical or freeze-drying, the products are aerogels and cryogels respectively. When drying under ambient condition is used, xerogels are produced, but these materials are characterised by large shrinkage during drying and have a collapsed pores network. This fact is caused by capillary forces, which destroy the pores during evaporation of the liquid [1].

The aim of this study is preparation of carbon material from cellulose acetate with a catalyst and a crosslinking agent using two different types of drying, and characterisation of prepared materials.

\section{Experimental}

\subsection{Synthesis of cellulose acetate gel}

The cellulose acetate-based hydrogel was synthesized according to the procedure reported in literature [5] with minor modifications. $20 \mathrm{~g}$ of cellulose acetate was dissolved in $140 \mathrm{~g}$ of acetone at room temperature with continuous stirring. After 24 hours, a transparent solution was obtained. $0.05 \mathrm{~g}$ of a DABCO catalyst $(33 \%$ solution of triethylenediamine in propylene glycol) and $4 \mathrm{~g}$ of a poly [(phenyl isocyanate)-co-formaldehyde] crosslinking agent were separately dissolved in $20 \mathrm{~g}$ of acetone and added to the acetate solution. The resulting mixture was poured into a bottle and the gel was aged for 1 week at room temperature.

\subsection{Drying}

Normal drying was performed by leaving the gel for several days at room temperature. Small, yellow, hard xerogels were obtained and named CA-N. Freeze-drying was performed using the FreeZone Freeze dry system device by Labconco. The pieces of gels were leached in distilled water and then frozen by immersing into liquid nitrogen. The frozen pieces were freeze-dried at $\sim 52 \mathrm{~Pa}$ for 48 hours to obtain cryogels named CA-FD.

\subsection{Pyrolysis}

The obtained xerogels or cryogels were pyrolysed in a flow of nitrogen $\left(150 \mathrm{ml} \mathrm{min}{ }^{-1}\right)$. The temperature program consisted of an initial isothermal step at $100^{\circ} \mathrm{C}(30 \mathrm{~min})$ followed by heating to $500^{\circ} \mathrm{C}$ with a heating rate of $10 \mathrm{~K} \mathrm{~min}^{-1}$. This maximum temperature was then kept for 1 hour. The samples after pyrolysis were marked with an X (CA-NX, CA-FDX). 


\subsection{Sample analysis}

\subsubsection{Surface analysis}

The $\mathrm{S}_{\mathrm{BET}}$ values for porous characterisation of both samples after pyrolysis were obtained by dynamic nitrogen desorption at $-196^{\circ} \mathrm{C}$ using the CHROM4 device; $\mathrm{TiO}_{2}$ standards were used during the measurement. The microporous volume was calculated by the Dubinin-Radushkevich equation according to [6-8] from the data obtained by $\mathrm{CO}_{2}$ sorption. The carbon dioxide isotherms were measured using the Setaram PCTPro E\&E volumetric analyser at $30^{\circ} \mathrm{C}$ and at absolute pressure range from 0 to 1 bar. Microporous surface characterisations were acquired by the Medek's equation.

\subsubsection{FT-IR analysis}

The surface chemistry of the carbon materials was characterised by means of IR spectroscopy (Nicolet 6700). The samples (CA-N, CA-NX, CA-FD and CAFDX) were analysed in an attenuated total reflectance mode (ATR) with a single bounce diamond crystal. Each spectrum was obtained under $4 \mathrm{~cm}^{-1}$ resolution and a total of 64 scans were performed.

\subsubsection{Thermal analysis}

A thermal analysis (Setsys Evolution, Setaram) with an analysis of evolved gasses by a mass spectrometer (QMG 700, Pffeifer, coupled by Supersonic system, Setaram) was carried out from 20 to $1300^{\circ} \mathrm{C}$ with an isothermal step at $100^{\circ} \mathrm{C}$ with a heating rate of $10 \mathrm{~K} \mathrm{~min}^{-1}$ in an argon flow. Mass spectroscopy was used for observation of selected ions, which were generated during the thermoanalytical measurement.

\subsubsection{Adsorption analysis}

To determine the maximal adsorbed capacity, the sorption of methylene blue and $\mathrm{Cu}$ (II) from aqueous phase were performed as described in [9] with minor modifications. The adsorption experiments were carried out in small amount where $10 \mathrm{mg}$ of the sample after pyrolysis was placed in contact with $10 \mathrm{ml}$ of methylene blue or $\mathrm{Cu}$ (II) solution at various concentrations for 24 hours at room temperature with occasional shaking. In the case of methylene blue, the used initial concentrations were $1000,750,500,250,100,50,25$ and $10 \mathrm{mg} \mathrm{l}^{-1}$, concentrations after adsorption were analysed using the UV/VIS spectrometer (Varian Cary 50 Conc) at $645 \mathrm{~nm}$. In the case of $\mathrm{Cu}(\mathrm{II})$, the initial concentrations were $1.0,0.8,0.6,0.4,0.2$ and $0.1 \mathrm{mmol} \mathrm{l}^{-1}$. The adsorption data was gained by the atomic absorption spectrometer (Varian AA240FS). The adsorbed amount was calculated by the following equation:

$$
a=\frac{\left(c-c_{e}\right)}{100 . m}
$$

where a $\left[\mathrm{mg} \mathrm{g}^{-1}\right.$ or $\left.\mathrm{mmol} \mathrm{g}^{-1}\right]$ is the adsorbed amount, $\mathrm{c}\left[\mathrm{mg} \mathrm{l}^{-1}\right.$ or $\left.\mathrm{mmol} \mathrm{l}^{-1}\right]$ is the concentration before sorption, $\mathrm{c}_{\mathrm{e}}\left[\mathrm{mg} \mathrm{l}^{-1}\right.$ or $\left.\mathrm{mmol}^{-1}\right]$ is the equilibrium 
concentration after 24 hours, $\mathrm{m}$ [g] is the mass of the adsorbent (xerogel or cryogel).

\section{Results and discussion}

\subsection{Pore texture}

The porous characteristics of the analysed carbon materials are reported in Table 1. The specific surface areas measured by nitrogen desorption were $700 \mathrm{~m}^{2} \mathrm{~g}^{-1}$ for CA-NX and $770 \mathrm{~m}^{2} \mathrm{~g}^{-1}$ for CA-FDX. The microporous volume was $0.3 \mathrm{ml} \mathrm{g}^{-1}$ for both samples. The microporous surface area characterised by the Medek's equation was $820 \mathrm{~m}^{2} \mathrm{~g}^{-1}$ in the case of CA-NX and $860 \mathrm{~m}^{2} \mathrm{~g}^{-1}$ for CA-FDX.

Table 1: $\quad$ Porous characteristics for cellulose-acetate based materials.

\begin{tabular}{|c|c|c|c|}
\hline Sample & SBET $\left[\mathrm{m}^{2} \mathrm{~g}^{-1}\right]$ & VDUB $\left[\mathrm{mlg}^{-1}\right]$ & SMICRO $\left[\mathrm{m}^{2} \mathrm{~g}^{-1}\right]$ \\
\hline CA-N & $<10$ & - & - \\
\hline CA-FD & $<20$ & - & - \\
\hline CA-NX & 700 & 0.3 & 820 \\
\hline CA-FDX & 770 & 0.3 & 860 \\
\hline
\end{tabular}

The resulting data implies that the pyrolysis has a major influence on the surface properties of the final materials. Xerogel and cryogel have very low values of surface areas while $\mathrm{S}_{\mathrm{BET}}$ values of pyrolysed CA-NX and CA-FDX are in the hundreds of $\mathrm{m}^{2} \mathrm{~g}^{-1}$. It is apparent that the major reaction or reactions forming the resulting porous material take place during the pyrolysis.

\subsection{Thermal analysis and mass spectroscopy}

Figure 1 shows the resulting thermogravimetric (TG) and derivative thermogravimetric (DTG) curves for the pyrolysis of xerogel and cryogel. From the graphs it is evident that there is no significant difference between the analysed samples. The main mass loss occurs in the temperature range from 200 to $400^{\circ} \mathrm{C}$ but above this temperature, there is a next, less significant pyrolytic step. As mentioned above, the pyrolysis has a big influence on the porous characteristics of these samples and therefore, the temperature used for pyrolysis could be crucial. Regarding the gradual final step of the pyrolysis, it would be desirable to use a temperature of at least $600^{\circ} \mathrm{C}$ during this treatment.

The gases evolved during the pyrolysis of xerogel as well as cryogel were analysed by mass spectroscopy to better understanding what happens in the sample. For both materials, a water loss was observed at a temperature about $100^{\circ} \mathrm{C}$ (residual moisture) and another loss of water occurred in the range from 200 to $500^{\circ} \mathrm{C}$ (Figures 2 and 3). 


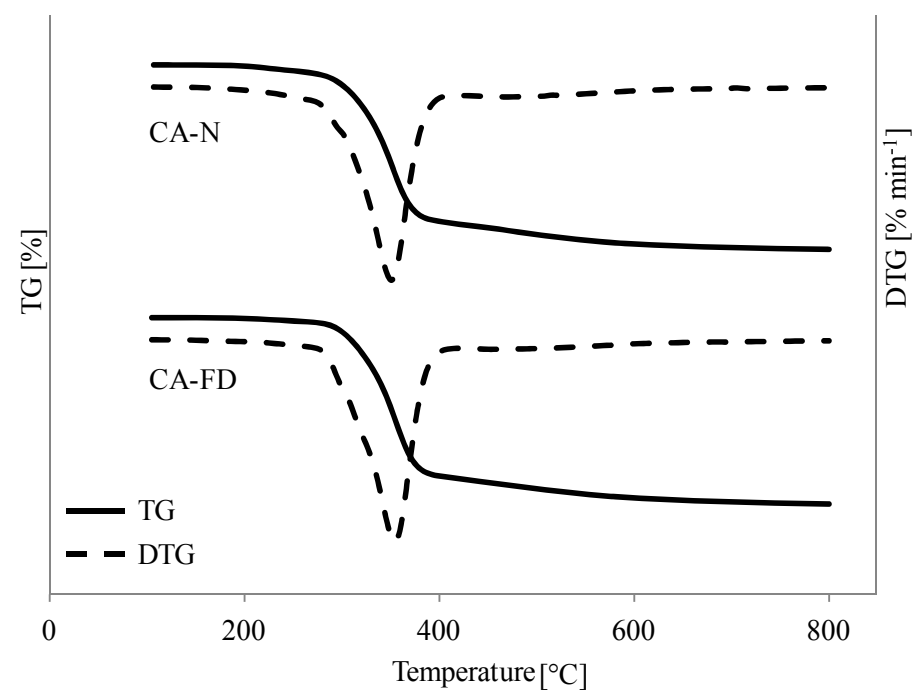

Figure 1: $\quad$ The TG (a) and DTG (b) curves of CA-N and CA-FD pyrolysis.

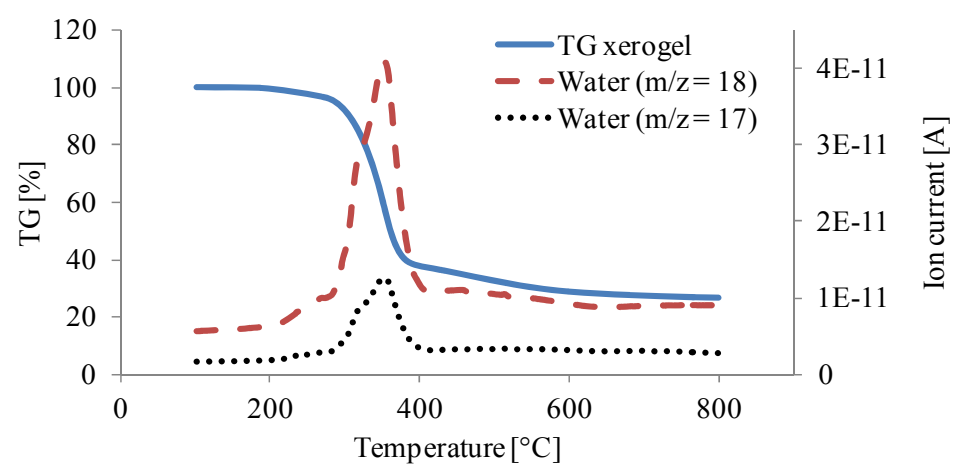

Figure 2: $\quad$ Water loss during xerogel CA-N pyrolysis.

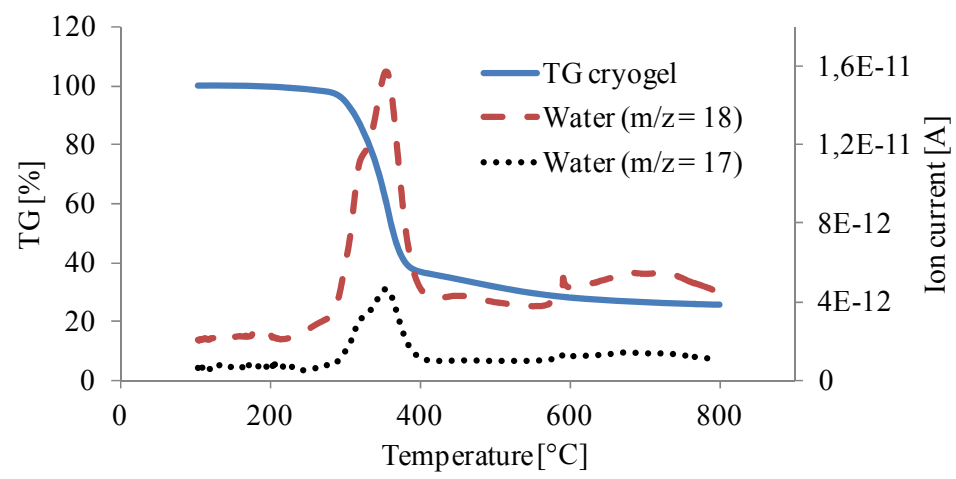

Figure 3: Water loss during cryogel CA-FD pyrolysis. 
During the preparation of CA, carbon dioxide was generated as a result of the reaction between water and PMDI. $\mathrm{CO}_{2}$ was created in the form of little bubbles immediately after pouring the PMDI solution into dissolved cellulose acetate. As can been seen on the MS spectra, which are the same for both analysed gels, the residual water and carbon dioxide were released during the main thermal decomposition step (Figures 4 and 5). Maybe, not all water is reacted with PMDI and this reaction could have taken place at a higher temperature or some generated $\mathrm{CO}_{2}$ could have been bonded in the structure of xero or cryogel and released during the pyrolysis. It is clear that some $\mathrm{CO}_{2}$ left the structure, because the shape of the samples was totally different after the pyrolysis - from small, hard and almost non-porous material, porous, black carbon xerogel or cryogel was made.

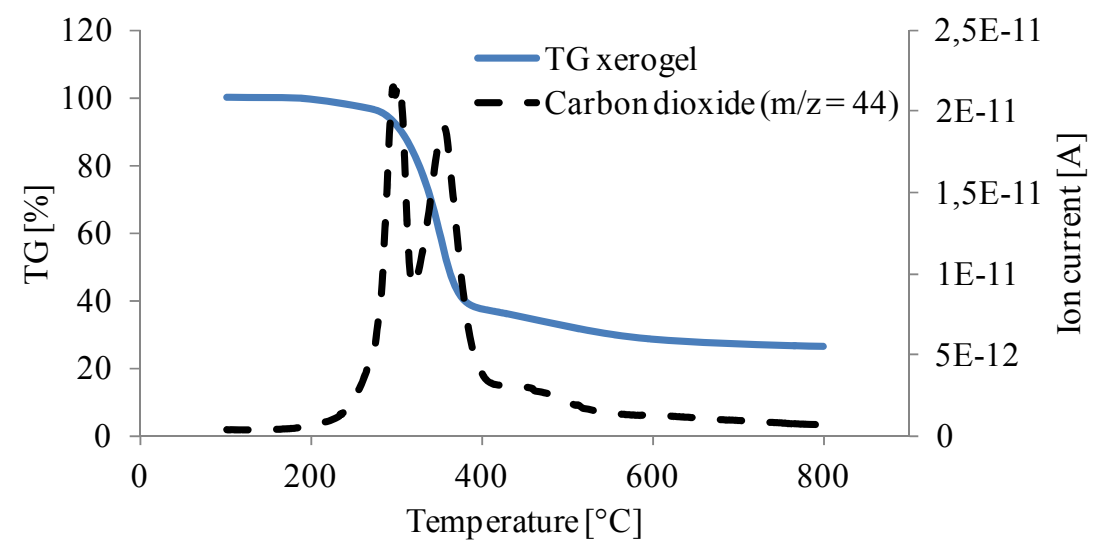

Figure 4: $\quad$ Release of carbon dioxide during xerogel CA-N pyrolysis.

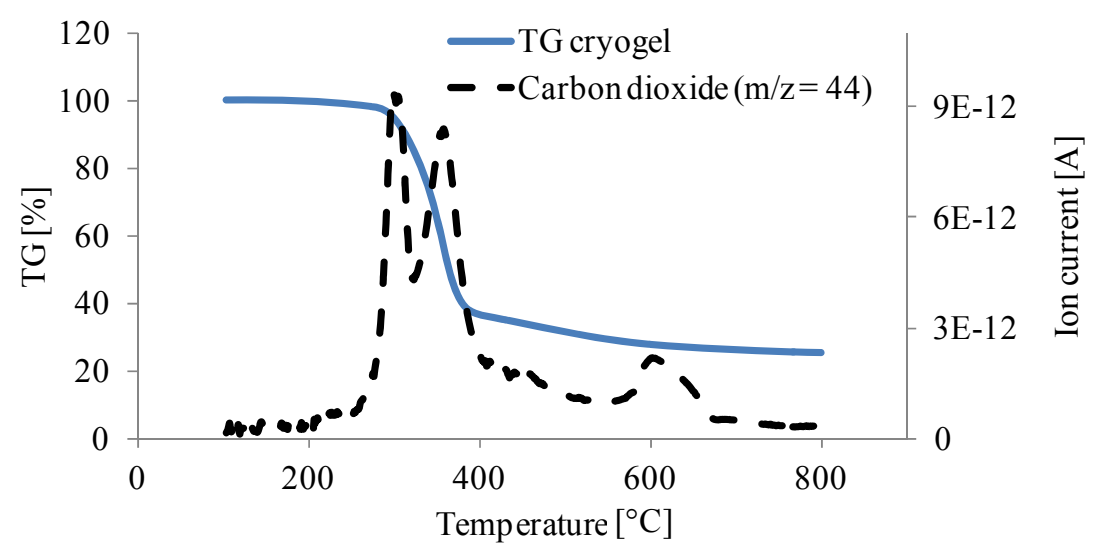

Figure 5: Release of carbon dioxide during cryogel CA-FD pyrolysis. 


\subsection{Infrared spectroscopy}

Xerogel and cryogel as well as their pyrolysed forms were analysed by FT-IR to determine their surface chemistry (Figures 6 and 7). The spectra of both cryogels and xerogels are very similar and therefore, a more detailed description is provided only for xerogel. The distinction between the materials before $(\mathrm{CA}-\mathrm{N}$, CA-FD) and after (CA-NX, CA-FDX) the pyrolysis is evident from the FT-IR record. For CA-N, the adsorption bands at 2923 and $2854 \mathrm{~cm}^{-1}$ correspond to the $\mathrm{C}-\mathrm{H}$ aliphatic bonds and the value of $1367 \mathrm{~cm}^{-1}$ can be attributed to the deformation mode of the $\mathrm{C}-\mathrm{H}$ bond. The peaks at 1512 and $1537 \mathrm{~cm}^{-1}$ can be associated with the urethane bonds, which was generated during the preparation of the acetate gel. The wide peak at $3479 \mathrm{~cm}^{-1}$ can be probably attributed to the NH group. The peaks at 1736, 1217 and $1034 \mathrm{~cm}-1$ can indicate the presence of the $\mathrm{C}=\mathrm{O}$ and $\mathrm{C}-\mathrm{O}$ structures. For $\mathrm{CA}-\mathrm{NX}$, it is clear, that the spectrum is poorer, the sharp peaks disappeared and instead of them, wider and less identifiable peaks are present. Some small peaks at 3400 and $3055 \mathrm{~cm}^{-1}$ indicate that the structure is aromatic. The peak at 1587 and $1417 \mathrm{~cm}^{-1}$ can be attributed to the $\mathrm{C}=\mathrm{C}$ and $\mathrm{C}=\mathrm{N}$. Three peaks at 876,802 and $746 \mathrm{~cm}^{-1}$ may be associated with aromatic rings. The pyrolysis is likely to cause the degradation of oxygen functionalities which is confirmed by the disappearance of the peaks at 1736, 1217 and $1034 \mathrm{~cm}^{-1}$.

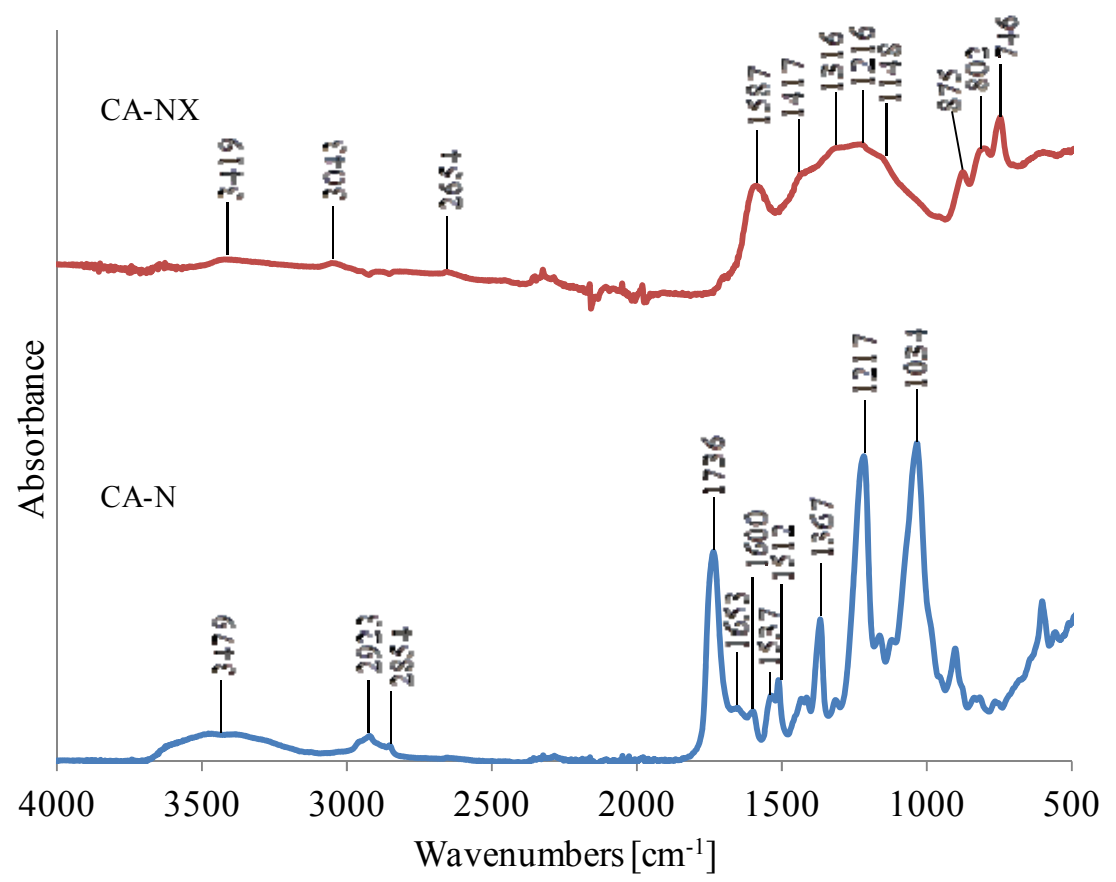

Figure 6: The FT-IR analysis of CA-N and CA-NX. 


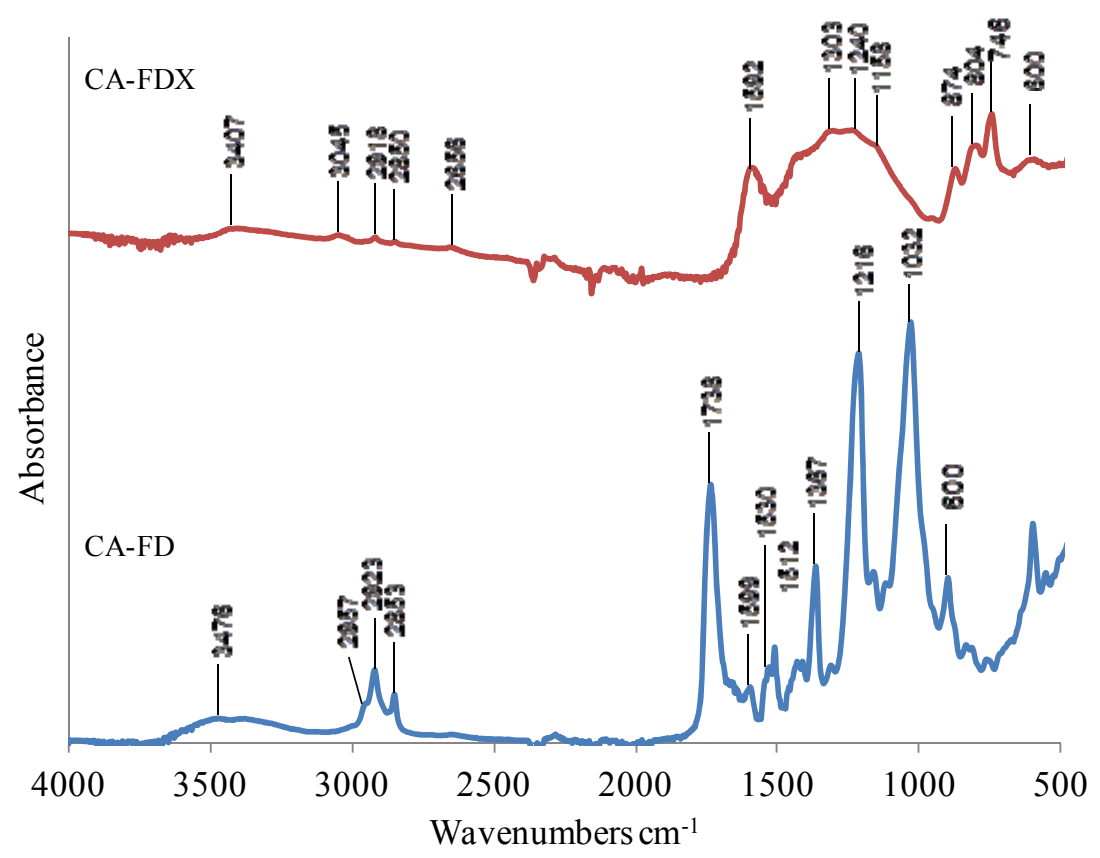

Figure 7: $\quad$ FT-IR analysis of CA-FD and CA-FDX.

\subsection{Sorption experiments}

The obtained data of concentration and adsorbed amount were plotted to get the maximal adsorption capacity which is defined as the maximum amount of adsorbed substance related to $1 \mathrm{~g}$ of sorbent. This experiment was repeated three times to obtain three adsorption curves. The maximal adsorption capacity was about $100 \mathrm{mg} \mathrm{g}^{-1}$ for CA-NX and about $200 \mathrm{mg} \mathrm{g}^{-1}$ for CA-FDX (Figure 8). There is a significant difference between the used sorbents and better sorption ability is probably a results of the freeze-drying technique applied during the preparation, which preserved an open porous structure with less damages.

In addition, the sorption of copper ions was performed. The experiment was carried out as mentioned above in the case of methylene blue in the same ratio of $10 \mathrm{mg}$ of sorbent (xerogel or cryogel) and $10 \mathrm{ml}$ of copper solution. In the case of $\mathrm{Cu}(\mathrm{II})$, sorption was also repeated to obtain three curves. The maximal adsorption capacity was calculated according to equation (1) and it was about $0.12 \mathrm{mmol}^{-1} \mathrm{l}^{1}$ for xerogel and about $0.25 \mathrm{mmol} \mathrm{l}^{-1}$ for cryogel (Figure 9). The difference between the used adsorbents is apparent; cryogel has a higher adsorption capacity, especially at higher concentrations. 


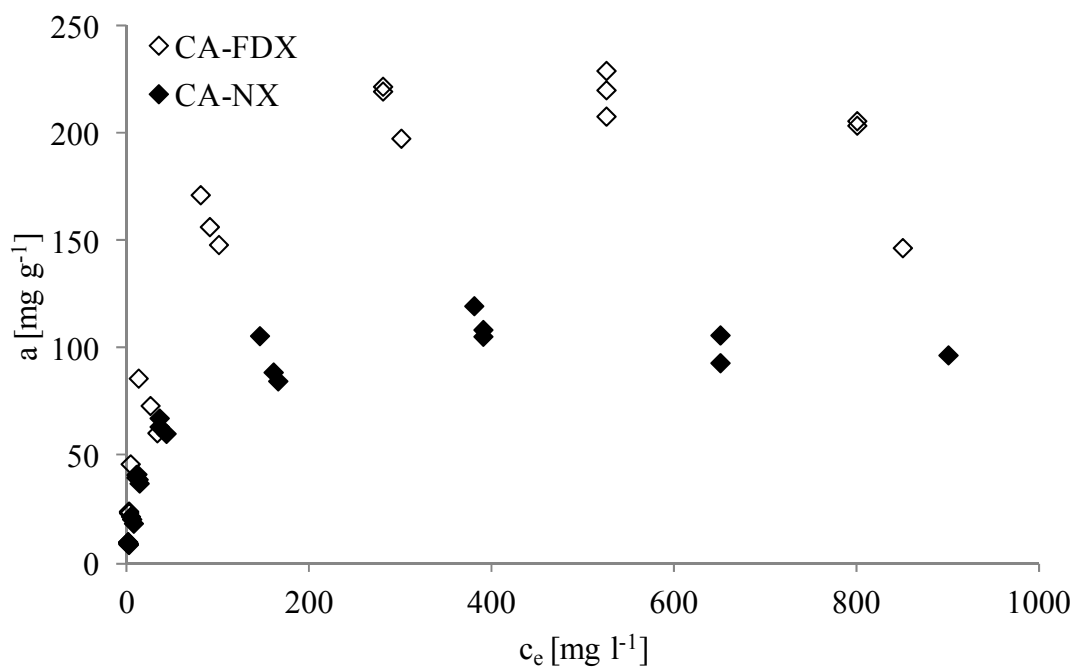

Figure 8: The adsorption isotherms of methylene blue on CA-NX and CA-FDX.

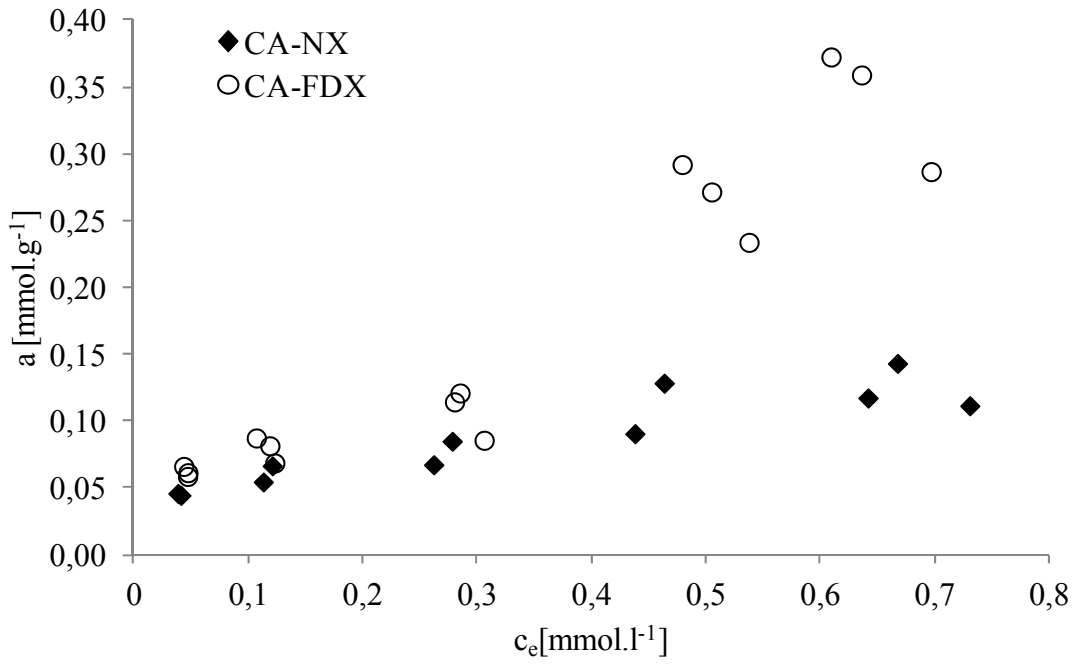

Figure 9: The adsorption isotherm of $\mathrm{Cu}(\mathrm{II})$ on samples $\mathrm{CA}-\mathrm{NX}$ and CA-FDX. 


\section{Conclusion}

The present paper describes the preparation of carbon xerogels and cryogels from cellulose acetate. The resultant materials and their pyrolysed forms were analysed by various techniques to obtain complex information of their properties. From a chemical point of view, xerogel and cryogel are very similar; they have almost identical surface chemistry, thermal behaviour and porous structures. The volume of pores was $0.3 \mathrm{ml} \mathrm{g}^{-1}, \mathrm{~S}_{\mathrm{BET}}$ values were from 700 to $770 \mathrm{~m}^{2} \mathrm{~g}^{-1}$ and $\mathrm{S}_{\text {micro }}$ was about $850 \mathrm{~m}^{2} \mathrm{~g}^{-1}$. During the adsorption experiments, it was observed that freeze-dried materials have better adsorption abilities in the adsorption of organic dye and $\mathrm{Cu}(\mathrm{II})$ from aqueous phase. The maximal adsorption capacity was almost twice as high compared to xerogel. This suggests that during preparation, freeze-drying is a sensitive method which prevents the nanoporous network of gels from collapsing and preserves an open pores structure in contrast to normal drying. Their high surface area, adsorption ability and the fact that xerogels and cryogels are made from a biodegradable resource make these materials ideal candidates for various applications.

\section{Acknowledgements}

This study was performed in connection with a project Institute of Environmental Technologies, reg. No. CZ.1.05/2.1.00/03.0100 supported by the Research and Development for Innovations Operational Programme financed by the Structural Funds of the European Union and from the means of state budget of the Czech Republic. The University of Ostrava supported this research by means of SGS reg. No. SGS02/PřF/2013.

\section{References}

[1] Hüsing, N. and Schubert, U., Aerogels-airy materials: chemistry, structure, and properties. Angew. Chem. Int. Ed., 37, pp. 22-45, 1998.

[2] Innerlohinger, J., Weber, H. K. and Kraft, G., Aerocellulose: Aerogels and aerogel-like materials made from cellulose. Macromol. Symp., 244, pp. 126$135,2006$.

[3] Deng, M., Zhou, Q., Du, A., van Kasteren, J. and Wang, Y., Preparation of nanoporous cellulose foams from cellulose-ionic liquid solutions. Materials Letters, 63, pp. 1851-1854, 2009.

[4] Paljevac, M., Primožič, M., Habulin, M., Novak, Z. and Knez, Ž., Hydrolysis of carboxymethyl cellulose catalyzed by cellulase immobilized on silica gels at low and high pressures. J. of Supercritical Fluids, 43, pp. 74-80, 2007.

[5] Grzyb, B., Hildenbrand, C., Berthon-Fabry, S., Bégin, D., Job, N., Rigacci, A. and Achard P., Functionalisation and chemical characterisation of cellulose-derived carbon aerogels. Carbon, 47, pp. 2297-2307, 2010.

[6] Medek, J., Possibility of micropore analysis of coal and coke from the carbon dioxide isotherm. Fuel, 56, pp. 131-133, 1977. 
[7] Medek, J. and Weishauptová, Z., Vliv mikropórovitosti koksů na jejich vlastnosti, 1. část - Mikropórovitost jako charakteristická složka porézní struktury koksů. Uhlí, 35, pp. 170-174, 1987 (in Czech).

[8] Lowell, S., Shields, J.E., Thomas, M.A. and Thommes, M., Characterisation of porous solids and powders: Surface area, pore size and density, Springer: Dordrecht, pp. 29-33, 2004.

[9] Nunes, C. A. and Guerreiro, M. C., Estimation of surface area and pore volume of activated carbons by methylene blue and iodine numbers. Quim. Nova, 34(3), pp. 472-476, 2011. 